\title{
Evaluation of Seismic Retrofitting Techniques Used in Old Reinforced Concrete Buildings
}

\author{
Ahmed Abdelrahem Farghaly ${ }^{1}$ and Ali Mohamed Abdallah ${ }^{2}$ \\ ${ }^{I}$ (Civil and Architectural Building, Faculty of Industrial Education, Sohag University, Egypt) \\ ${ }^{2}$ (Civil Engineering Department, Faculty of Engineering, Kafrelsheikh University. Kafrelsheikh, Egypt)
}

\begin{abstract}
Past earthquakes have emphasized the vulnerability of existing structures which did not satisfy modern seismic design requirements and current engineering standards even though they may have been properly designed and constructed according to earlier codes. Many existing buildings may be inadequate and pose severe risk during seismic events. To mitigate the seismic hazard, existing building should be rehabilitated. The rehabilitation measures to upgrade the capacity of these structures can be performed at some point in their useful lives. The evaluation of the seismic capacity of existing buildings and their deficiencies is essential for the design of a rehabilitation technique. The aim of the evaluation and rehabilitation systems is either for collapse prevention to ensure safety of the occupants or to control the damage to ensure the continuity of operation during and after earthquakes. In this paper several retrofit techniques was evaluated by applicable them on different kinds of existing structures to find the best one will be used for each kind of tested structures. Four retrofit techniques (R.C. walls, steel bracing, column jacket, and column strengthen by 4 steel angles each corner) were tested for each selected four existing structure. By examine each technique on each tested structure, the values of top displacement, top floor acceleration, max. base shear, and period time of first mode were varied by response of each applied retrofit techniques and the minimum response will be the choose as arbitrator between different kinds of used techniques to use it as the optimal technique used to retrofit this structure.
\end{abstract}

KEY WORDS: retrofit; repair/strengthening; rehabilitation; structural intervention.

\section{INTRODUCTION}

Many existing structures in high risk earthquake areas are inadequate in their ability to withstand seismic loads. Although these building were designed and constructed following the structural codes in effect at the time, their lateral load resisting systems are deficient in terms of the stricter and more complex codes of today. Often, an owner will choose to strengthen, as well as repair, a building damage by an earthquake rather than construct a new building. Other reasons for seismic strengthening include force compliance with local building codes caused be changes in occupancy, and voluntary measures taken by owners for safety of financial interests.Figure 1 represents rehabilitations techniques used in some buildings in Japan. The most used technique is adding shear wall the existing buildings then using column jacket and the minimum technique used is adding steel bracing and reinforcement beams.

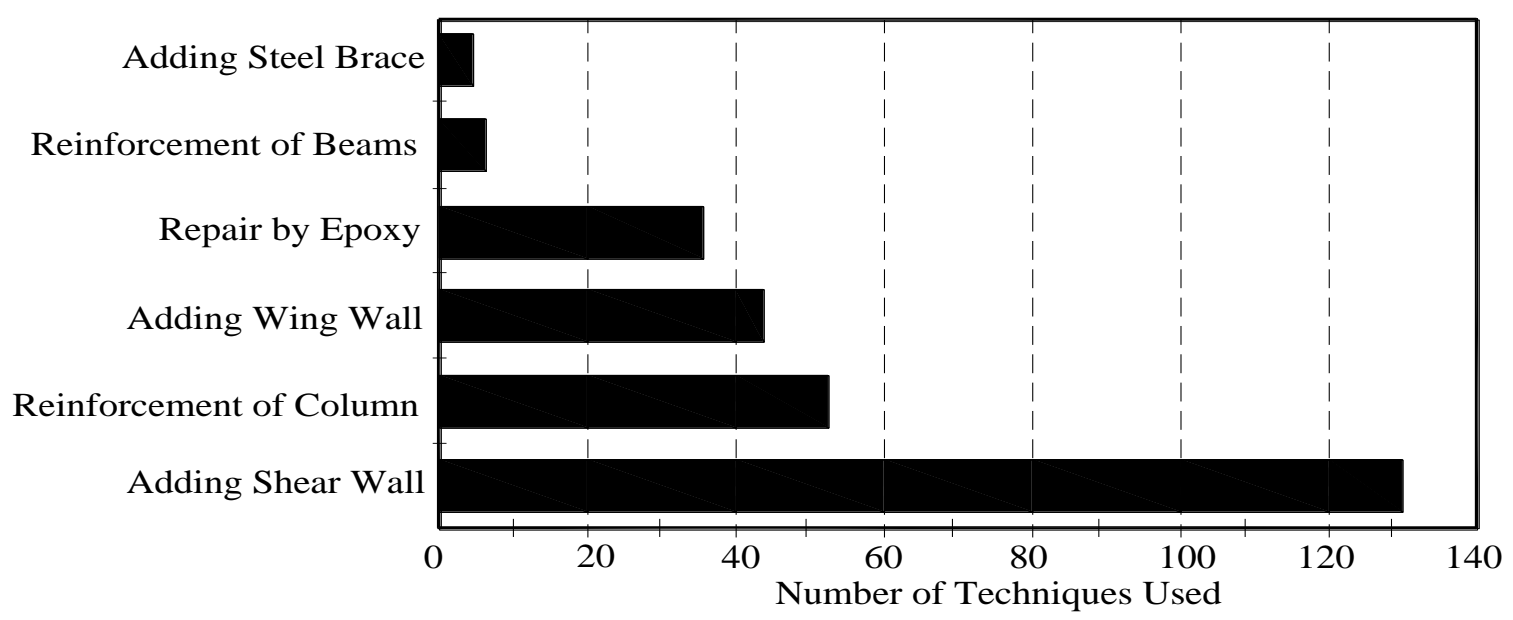

Fig. 1: Rehabilitations techniques used in some building in Japan (Gajanan et al. 1996) [5] 
Very little guidance is available for formulating the rehabilitation strategy for the structure. An interesting study on selective rehabilitation of short walls was conducted by Elnashai and Pinho (1998)[4]. Figure 2 shows the relation between shear force and displacement for different kinds of retrofit techniques. Maximum shear force and minimum displacement values were recorded in the monolithic wall retrofit case, and minimum shear force and maximum displacement were observed in the column with wing walls retrofit case. The techniques of retrofit changing the behavior of the structure under lateral force (earthquake effect), so for different kinds of structure system there is a suitable technique to be used in rehabilitation operation.

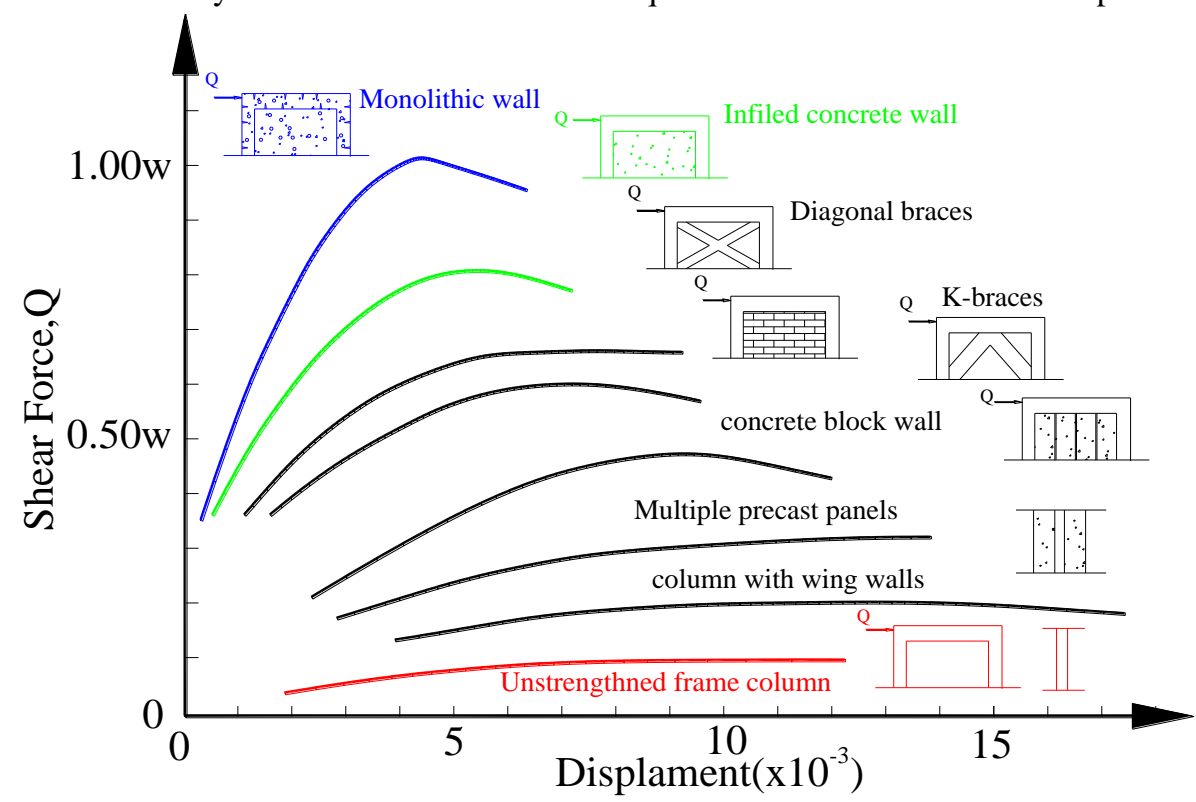

Figure 2: Relation between shear forces and displacement in different kinds of strengthen techniques (Ambrose and Vergun, 1995) [2]

To achieve the rehabilitation objectives of a specified damage level, collapse prevention or life safety, different design strategies may be adopted. The relationship between strength and ductility shown in Figure 3, shows that the required strength diminishes with increasing the ductility because of the improved inelastic behavior and energy absorbing characteristics of the system. If the structure is to resist a given earthquake with minimal damage to the structure or its contents, the main concern will be the control of drift and the required strength will not be ductility dependent. A maximum drift limit can be established to protect against damage to nonstructural elements. The combination of collapse prevention and various damage levels produce a curve that divides the strength-ductility plane into adequate and inadequate zones as shown in Figure 3 (Ghobarah, 2000)

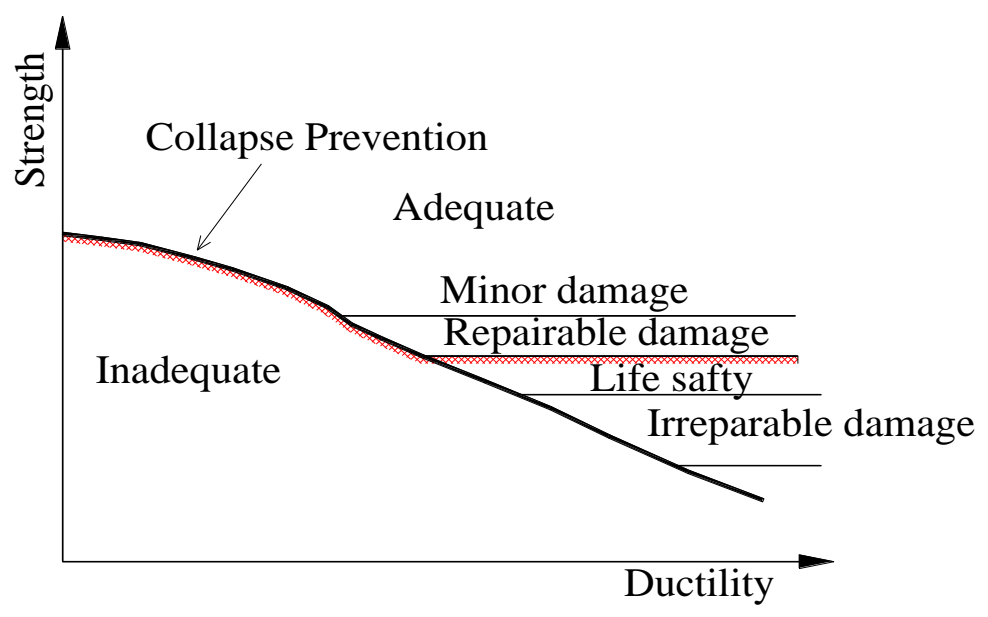

Figure 3: Typical ductility - strength relationship (Ghobarah, 2000) [6]

The strengthening solutions were selected in order to obtain technical and economical advantages: safe behavior at seismic action; 
slight change of general structural stiffness; easy strengthening technology and short refurbishment period; low rehabilitation cost. (Cornrlui et al. 2007) [3] Seismic rehabilitation of existing deficient structures should be the major current concern in the field of earthquake engineering. The choice of a specific technique for rehabilitation requires an engineering judgment as it depends on many factors including economic considerations, the function of the building, architectural considerations and the relative simplicity of different methods. An important outcome of the analysis is that special care has to be taken in the selection and design of a specific selective retrofit technique. It is necessary to evaluate the implications of the retrofit schemes on the performance of the structure. The prediction of displacement, top floor acceleration, time period and base shear provided simple and effective criteria for the selection and design of the retrofit scheme. The time history analysis does not account for dynamic effects such as stiffness changes which affect seismic demand.

\section{The Used Retrofit Techniques}

- Concrete Jacketing

Concrete jacketing was used to increase axial, flexural, and shear strength of existing elements, increases in ductility and stiffness were also achieved. Jacketing was performed by adding longitudinal and transverse reinforcement or a welded wire mesh surrounding the original section and covering it with new cast in place concrete or with shotcrete. Surface roughening of the original section was performed by sandblasting or by mechanical means to improve monolithic behavior of the elements. In general, columns are regarded as the most critical structural members to be rehabilitated, since the failure of columns may lead to collapse (Moehle, 2000)[7].

\section{- Concrete Structural Walls}

Adding concrete walls by infilling certain frame bays with reinforced concrete is popular for seismic retrofitting, but is covered by codes only if the connection of the old concrete to the new ensures monolithic behavior. Walls, when adequately anchored into the surrounding frame using various types of connections (e.g., shear keys, dowels, chemical anchors) not only increase the lateral stiffness of the building significantly, but also relieve the existing non-ductile frames from being subjected to large lateral force demands. The critical issue in prediction of the seismic performance of a building strengthened with shear walls is the distribution of lateral earthquake forces to the walls and the frame (staggered distribution models (1) and (2)).

\section{- Steel Bracing}

Space and lighting limitations in a structure may make it desirable to use steel bracing instead of concrete structural walls. In addition, steel bracing may be more easily and rapidly installed. By using two angles back to back with size $100 \times 100 \times 10 \mathrm{~mm}$ as X steel bracing with different distributed models at the outer parameter of the tested models (staggered distribution models (1) and (2))

In all these solutions, the critical issue is the bond and shear connection between new and existing layers. The repair materials that were used in strengthen building had to meet the following characteristics:

1. Be durable and protect reinforcement.

2. Be dimensionally stable to avoid loss of contact between the old and new materials due to shrinkage.

3. Provide good bond between the new and old materials, including bond between steel and concrete elements.

4. Be able to develop adequate resistance at early ages, especially if the capacity of a damaged element had to be restored rapidly.The properties of repair materials had to be similar to the existing material properties to avoid creating overstresses in the old material. The elastic modulus and time or temperature effects on the materials had to be compatible with existing materials to avoid problems under high stresses, sustained loads, or temperature changes (Teran 1988)[8]. In the case where new concrete was used to repair an element, the new concrete compressive strength was at least equal to the existing concrete strength. However, the difference in strength had to be given special consideration to avoid failure and crushing in the lower strength materials.Structure retrofitting is one of the widely used techniques for upgrading the lateral load carrying capacity of reinforced concrete buildings. Upgrading the structures performance normally involves increasing its strength, ductility, stiffness or in most cases a combination of two or the three parameters. However, it is not clear what is the effect of each strategy on the overall behavior of the structure in terms of top displacement, time period, maximum shear force, and top floor acceleration when subjected to a design ground motion. Although in most cases it is difficult to change the stiffness without affecting the strength and ductility of a structure, the effect of the change in each aspect of behavior will be examined separately in order to investigate the selective and targeted rehabilitation strategies for the structures. 
Ahmed and Ali (2012) [1] studied performance based assessment methods and basic principles given in ECOL2008 and real time history analysis (TM) and a real three dimensional case study building and the results are compared. The authors showed that the performing methods of analysis with approaches using either ECOL2008 or TM independently produce a difference performance level for the critical storey of the two studied (old and new school buildings) structures. The cases study buildings are found to be as in safety performance level for new version school building designed after the 1992 Egyptian earthquake but not for the one who designed before the earthquake. The computed base shear value according to TM is higher than the ECOL2008 Code, while the selected ground conditions represent the same characteristics. The main reason is that the ordinate of the horizontal elastic response spectrum for ECOL2008 is increased by the soil factor. It is also observed that the demand storey drafts obtained from two methods of analysis are difference in values. The ECOL2008 code for design such kinds of building satisfy conditions for earthquake loads. For the safety conditions the old version of the school building, which affected by the 1992 Egyptian earthquake of not it must be strengthened as the technical procedure to resist any future Earthquakes, which the study showed the probably collapse if they expose to anther earthquake.

\section{MODEL DESCRIPTION}

Figure 3 shows the 4 models used to be retrofitted with different techniques used in Egypt. These structures (models) consist of reinforced concrete frames with beams and columns as part of the lateral and vertical resisting system. The floor system is a reinforced concrete two way or one way slab supported directly on the frame beams or on interior beams. Typical slab thicknesses range from 10 to $14 \mathrm{~cm}$ and the slabs are usually cast in place. Usually, frame buildings have a high density of partition masonry. Partitions are considered to be non-structural in building design. The lateral forces are entirely resisted by the beams and columns that constitute the building frames. Therefore, the stiffness of these elements determines the dynamic response. The distance between columns depends on the use of the building; with greater spans for office buildings (spans can be 4 to $5 \mathrm{~m}$.). However, the beam depth has often been limited due to architectural considerations, and as a consequence, beam stiffness has been drastically reduced, making the frames very flexible under lateral excitations. The objective of this study is to assess the seismic performance of existing 5storey, 6-storey and 11-storey reinforced concrete buildings and to evaluate the effectiveness of different rehabilitation strategies were used. The selective upgrade strategies include increasing the structures strength, stiffness, improving ductility or a combination of these approaches. The analysis will provide the basis for decisions concerning the rehabilitation strategy for non-ductile reinforced concrete frames and the design of selective rehabilitation techniques. By inspection of the given models, figure 3-i shows the structural plane of model (1), which contains ground and 4 floors and figure 3-ii shows model (2) contains ground and 5 floors, figure 3-iii shows model (3) contains ground and 4 floors, and figure 3-iv represents model (4) c contains bedroom, ground and 10 floors.

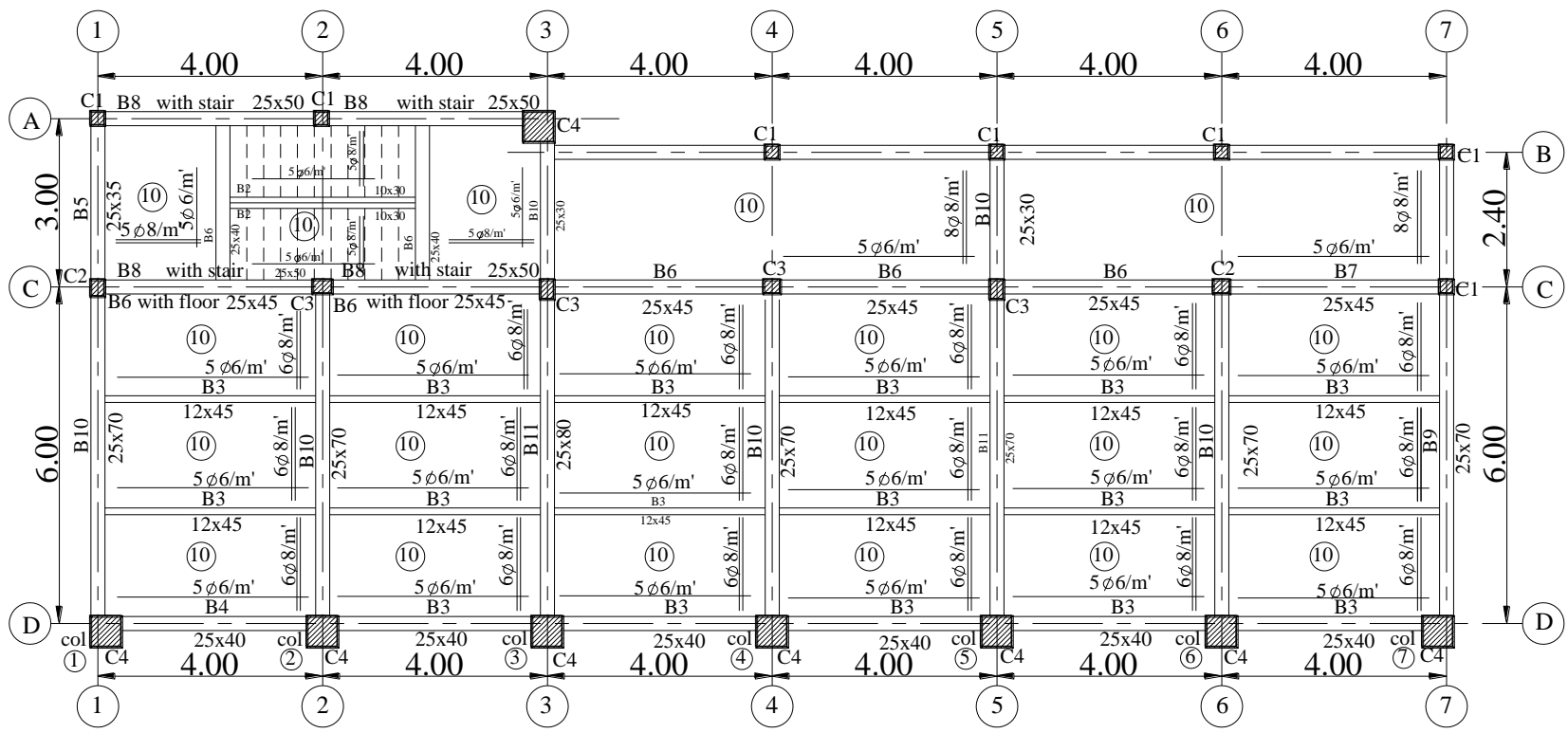

i) Model (1): Typical Storey Plan School building (Ground + 4 Floors) 


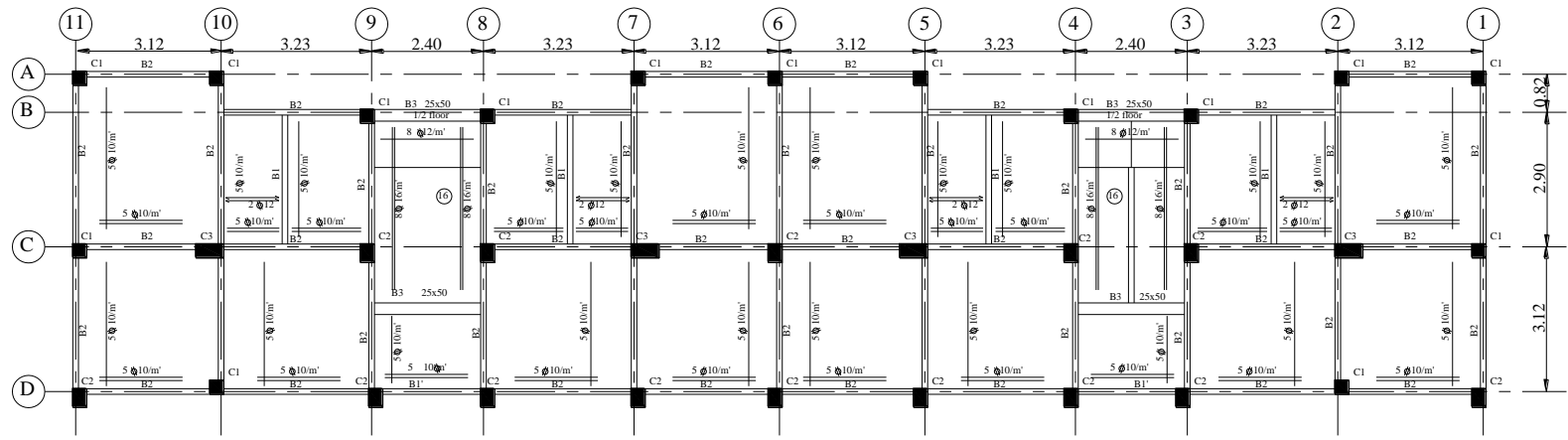

ii) Model (2): Frugal Residence (ground + 5 Floors)

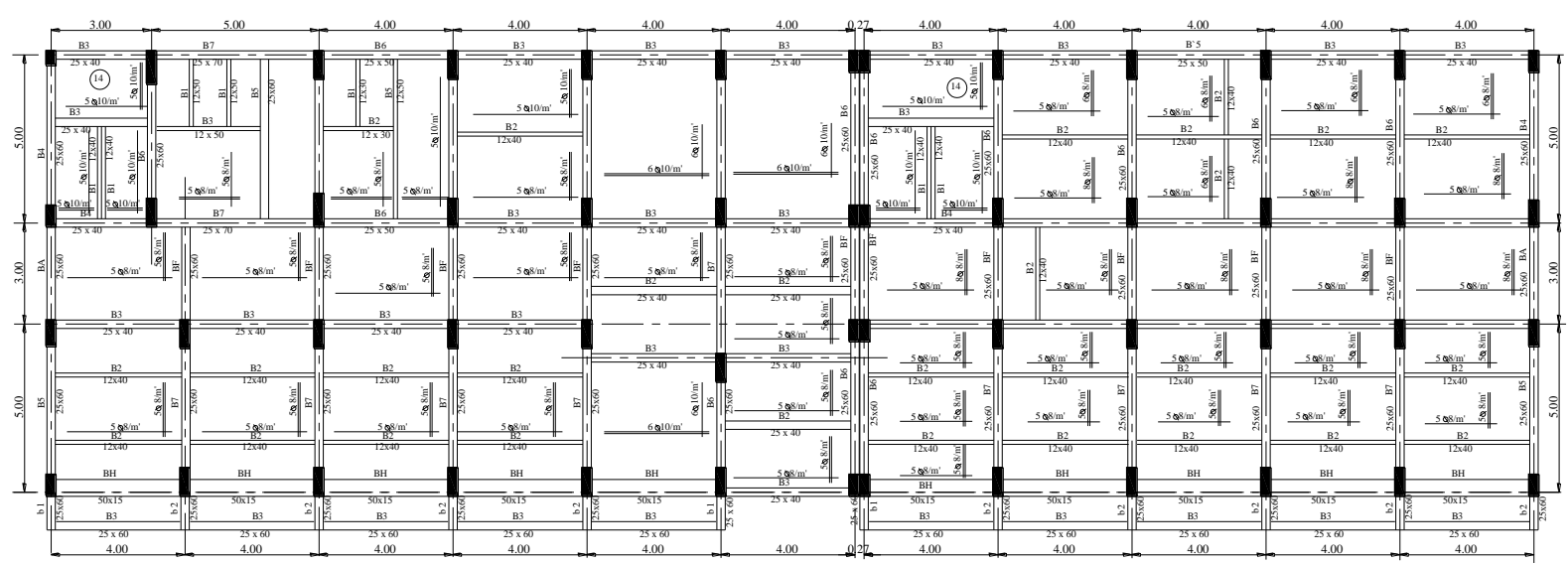

iii) Model (3): Healthy Concern building (Ground + 4 Floors)

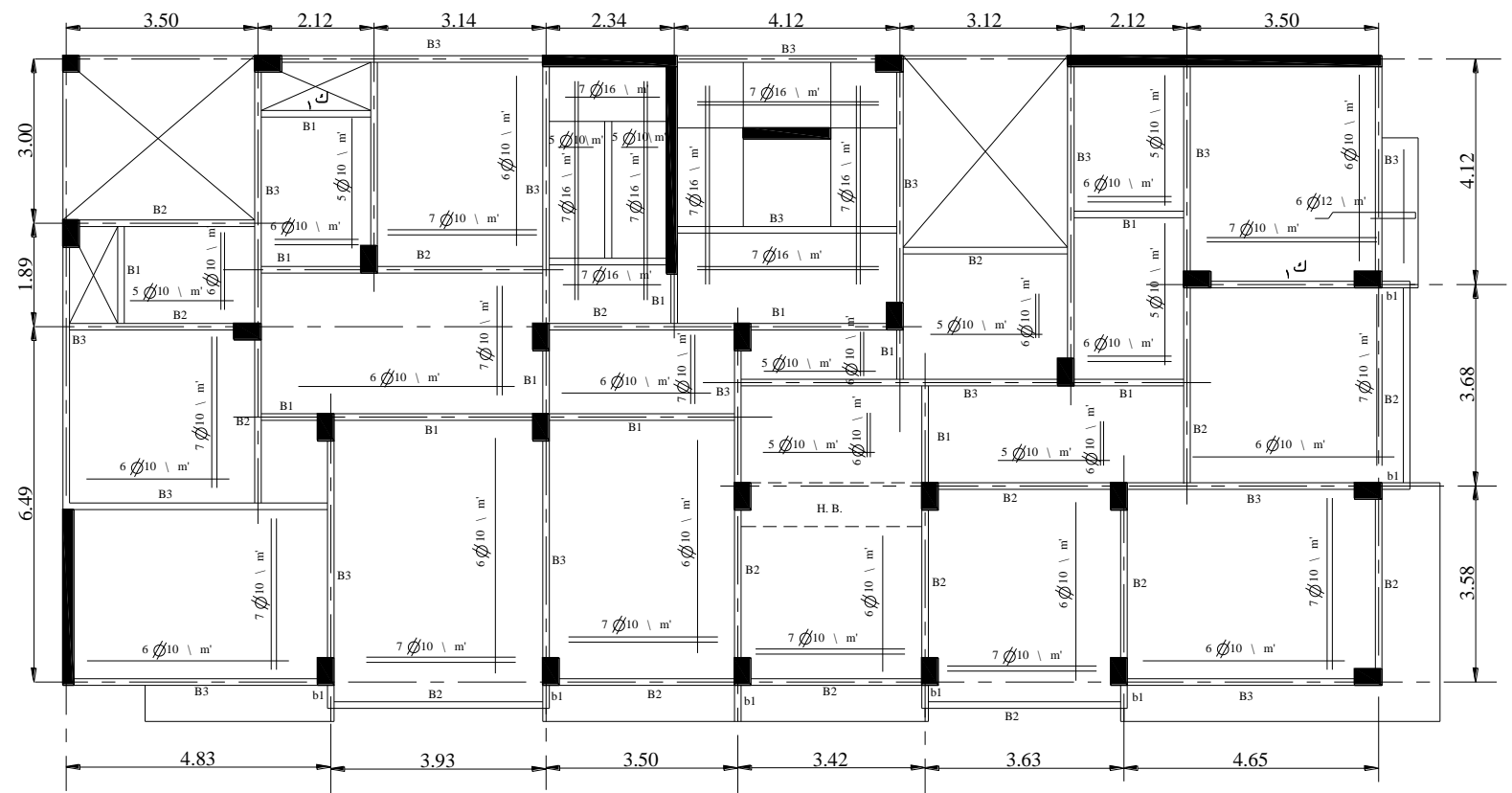

iv) Model (4): Tower buildings (bedroom +10 floors)

Figure 3: Structural Plane of Retrofitting Models.

Table 1 summarized the properties of each model, shows the effective parameters that may affect resistance earthquake force. The numbers of vertical elements (columns) of each model were calculated, and numbers of horizontal resisting elements (beams) also were calculated, so the effects of intensity of each element in each 
model were summarized in table 1 . The empty areas including stairs in each model were concluded in table 1 to show the internal spaces of each model.

Table 1: Parameters of the tested models

\begin{tabular}{|c|c|c|c|c|c|c|}
\hline Model & Description & $\begin{array}{c}\text { Area of Empty Space } \\
\text { (with stairs) }\left(\mathrm{m}^{2}\right)\end{array}$ & $\begin{array}{c}\text { Ratio (Length / } \\
\text { width) }\end{array}$ & No. of col. & $\begin{array}{c}\text { No. of beams } \\
\text { connected col. }\end{array}$ & Total Area $\left(\mathrm{m}^{2}\right)$ \\
\hline$(1)$ & $\begin{array}{c}\text { Ground + } \\
\text { floors }\end{array}$ & 24 & 4 & 21 & 10 & 324 \\
\hline$(2)$ & $\begin{array}{c}\text { Ground + } \\
\text { floors }\end{array}$ & 19.2 & 4.4 & 33 & 14 & 205 \\
\hline$(3)$ & $\begin{array}{c}\text { Ground + } \\
\text { floors }\end{array}$ & 40 & 3.38 & 48 & 16 & 572 \\
\hline$(4)$ & $\begin{array}{c}\text { Badroom + 10 } \\
\text { floors }\end{array}$ & 42 & 2.1 & 31 & 19 & 273 \\
\hline
\end{tabular}

The ratio, between the actual values of ultimate bending moment and the necessary bending moment given by the present day seismic action level, were very low for columns, i.e. that meant that the building was characterized by a high risk of collapse at seismic actions. It results the necessity of structural rehabilitation.Figure 4 shows the response of each model with different retrofit techniques. Figure 4-a shows the top displacement response of models (1), (2), (3), and (4) under different retrofit techniques, the low value of displacement was observed in the RC. Wall (1) retrofit technique for model (1).Figure 4-b shows the top acceleration response of models (1), (2), (3), and (4) under different retrofit techniques, the low value of top floor acceleration was observed in the steel diagonal bracing (1) retrofit technique for model (2). Figure 4-c shows the base shear force response of models (1), (2), (3), and (4) under different retrofit techniques, the low value of max. base shear was observed in the RC. Wall (1) retrofit technique for model (3).

Figure 4-d shows the period time of first mode response of models (1), (2), (3), and (4) under different retrofit techniques, the low value of period was observed in the RC. Wall (1) retrofit technique for model (4).

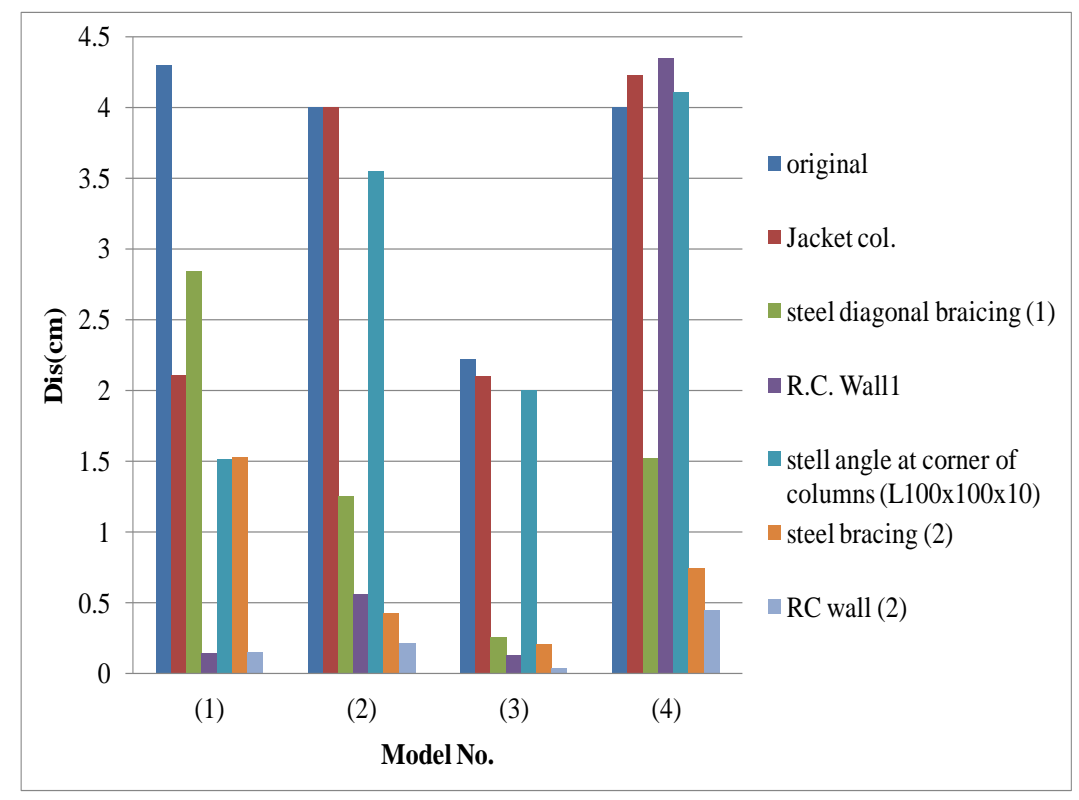

a) Top displacement 


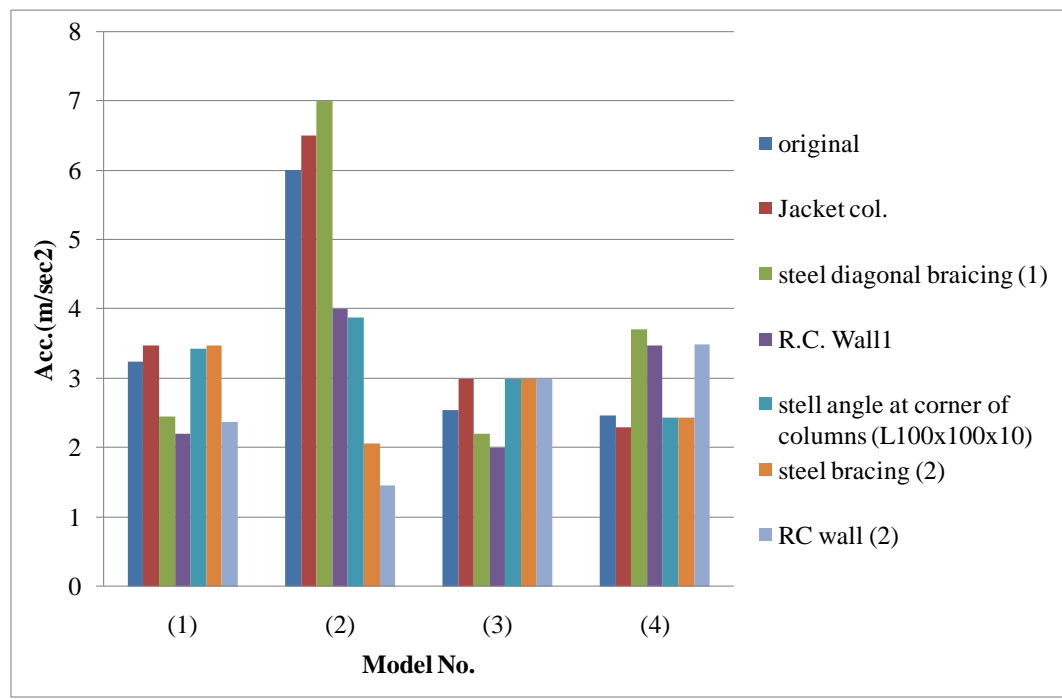

b) Top floor acceleration

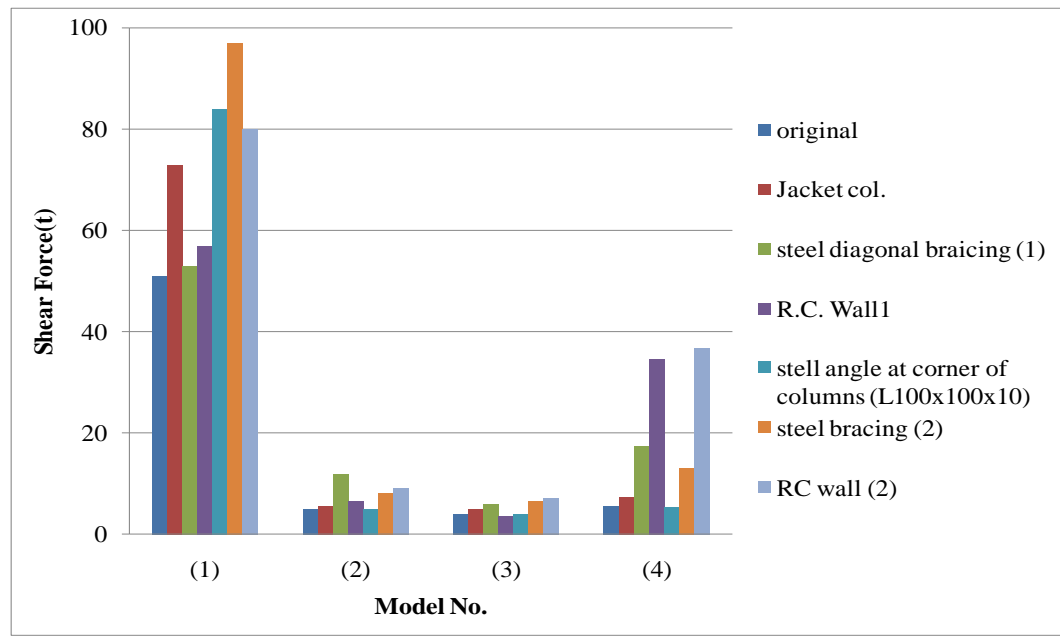

c) Max. base shear force

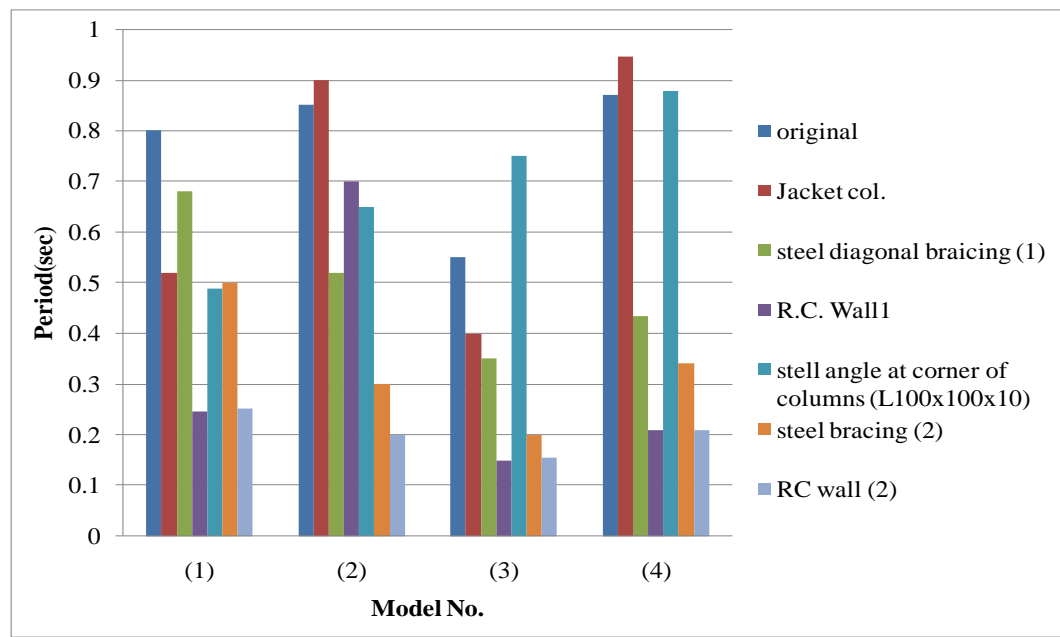

d) Period time of first mode (T)

Figure 4: Response of Retrofitting Models in Different Retrofit Techniques. 
The results of the analysis showed that for a low-rise building staggered RC. Walls (1) is the most effective rehabilitation technique for reducing displacement and damage. Increasing the ductility is associated with high top floor displacement and acceleration. In this case, early collapse may be prevented and the damage level is reduced due to increased energy dissipation. Increasing the stiffness of columns only was found to be detrimental as the frame attracted higher seismic forces. For medium-rise structures, increasing the column strength reduces the drift and damage. Increasing the column stiffness results in modest reduction in displacement and damage. The improvement of ductility resulted in modest reduction in damage and marginal effect on the story displacement due to the flexibility of the taller structure.

\section{CONCLUSIONS}

In this study, an investigation on seismic strengthening techniques of the RC existing buildings by column jacketing, steel bracing, and RC infill walls has been carried out. It is observed that the implementation of shear walls to the structural system has improved the capacity of the bare frame as expected. Main conclusions of the study are as follows:

(i) It was observed and measured that the newly added external shear wall and the connected end columns and beams behave like a monolithic member. Minor cracks between new and existing elements have been formed after $1 \%$ displacement. Even after these minor cracks, the shear walls did not lose their load bearing capacity.

(ii) Response modification factor $(\mathrm{R})$ is an important parameter for the seismic design of buildings.

In the experimental study, the strengthened model reached yield strength at about 4-5 mm roof displacement, where the base shear capacity started to fall after $23 \mathrm{~mm}$ of roof displacement. Therefore, a response modification factor of 4 to 5 can be used for strengthened buildings to determine the design force.

(iii) It has been proven that with the correct structural model, it is possible to create a successful design for strengthening the existing structures. However, further studies are needed to develop sliding shear models for nonlinear analyses of shear walled structures.

(iv) The strengthened model is a symmetric structure and therefore, uniform strengthening walls were used. In this case, the designer should keep in mind the possibility of a significant decrease in stiffness and the capacities of previously damaged elements, and consider that the level of the damage may significantly affect the cost of strengthening works. Consequently, strengthening of damaged buildings by exterior shear walls is an important topic for future researches.

(v) Comprehensive concrete RC walls staggered distribution in medium rise buildings, with a high density of columns, is a rehabilitation alternative that may not demand major changes in the foundation. It has the disadvantage that it may reduce the building's space more than other options, such as shear walls or steel bracing. The addition of shear walls, in most cases, required the addition of piles. Although driving piles is expensive, it is relatively easy in soils like those of Mexico City but, in other soils, may be a complicated construction problem. Occupancy may dictate the rehabilitation solution selected. The cost of disrupting operations may be much greater than the cost of construction. Some rehabilitation approaches were planned to disrupt only a portion of the building's occupants or operations. Documentation of rehabilitation projects is needed all over the world so that when earthquakes strike rehabilitated buildings, performance can be studied in considerable detail. Structural engineers need to continue to learn from experience and to share information.

(vi) The seismic strengthening system consisting of exposed structural steel diagonal braces greatly improved the performance of reinforced concrete model which had short columns and deep beams making up the exterior frame. The braces carried the lateral loads which would be produced by an earthquake and protected the columns from shear failure. For high rise building retrofit the concept of using steel bracing is one of the advantageous concepts which can be used to strengthen or retrofit the existing structures. Steel bracings can be used as an alternative to the other strengthening or retrofitting techniques available as the total weight on the existing building will not change significantly. Steel bracings reduce flexure and shear demands on beams and columns and transfer the lateral loads through axial load mechanism. The lateral displacements of the building studied are reduced by the use of X type of bracing systems. The building frames with $\mathrm{X}$ bracing system will have minimum possible bending moments in comparison to other types of bracing systems.

(vii) Retrofit techniques are not the same for different kinds of structures each having different parameters (no. of columns, tie beams no. of storey, area empty spaces, and total area of the structure) affecting the chosen of retrofit technique. 
Table 2 concluded the suitable techniques for each tested models in the study. The following table can be guiding in application method of retrofitting of various structures.

Table 2: Optimum used retrofit techniques for each tested models

\begin{tabular}{|c|c|c|c|}
\hline Models & Description & Ratio (Length / width) & Retrofit technique \\
\hline$(1)$ & Ground + 4 floors & 4 & Parameter staggered RC wall (1) \\
\hline$(2)$ & Ground + 5 floors & 4.4 & $\begin{array}{c}\text { Diagonal parameter staggered steel bracing } \\
\text { angels (1) (L100x100x10) }\end{array}$ \\
\hline$(3)$ & Ground + 4 floors & 3.38 & Parameter staggered RC wall (1) \\
\hline$(4)$ & Badroom + 10 floors & 2.1 & Parameter staggered RC wall (1) \\
\hline
\end{tabular}

\section{REFERENCES}

[1] Ahmed Abdelraheem Farghaly and Ali Mohamed Abdallah 2012," Comparative study on code-based linear evaluation of an existing R.C. school building before and after 1992 Egypt earthquake", Journal of Engineering Since, Assiut University, Vol. 40, No. 6, PP. 715-750.

[2] Ambrose, J. \& Vergun, D. - Simplified Building Design for Wind and Earthquake Forces - John Wiley \& Sons, INC.1995.

[3] Corneliu Bob, Sorin Dan, CǍTǍLIN Badea, Aurelian Gruin and Liliana Iureș "Rehabilitation of existing structures subjected to extreme events", Buletinul institutului politrhnic din IAŞI Tomul LIII (LVII), Fasc. 1-2, 2007 CovstrucȚ II. ArhitecturĂ.

[4] Elnashai, A.S. and Pinho, R. 1998. Repair and retrofitting of RC walls using selective techniques. Journal of Earthquake Engineering, Vol. 2, No. 4, 525-568.

[5] Gajanan, M. et al.1996-Seismic Rehabilitation of Concrete Structures- ACI, SP-160

[6] Ghobarah, Ahmed, "Selective Column Rehabilitation of RC Frames", 12WCEE, 2000.

[7] Moehle, J. P., 2000. State of research on seismic retrofit of concrete building structures in the US, Proceedings of the US-Japan Symposium and Workshop on Seismic Structures, Japan Concrete Institute, Tokyo, June 6 and 7, 2000.

[8] Teran, A., "Review of Repair Techniques for Earthquake Damaged Reinforced Concrete Buildings", Thesis presented to the Graduate School of the University of Texas at Austin in Partial Fulfillment of the Requirements for the Degree of Master of Science in Engineering, The University of Texas at Austin, December 1988. 